Article

\title{
Paper-Based Vapor Detection of Formaldehyde: Colorimetric Sensing with High Sensitivity
}

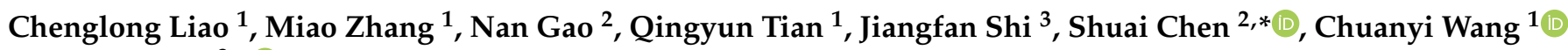 \\ and Ling Zang $3, *(\mathbb{D}$
}

1 School of Environmental Science and Engineering, Shaanxi University of Science and Technology, Xi' an 710021, China; lc16862@163.com (C.L.); miaozhang1209@163.com (M.Z.); tianqingyun2017@163.com (Q.T.); wangchuanyi@sust.edu.cn (C.W.)

2 Jiangxi Engineering Laboratory of Waterborne Coatings, Nanchang 330013, China; gaonan2019@163.com

3 Department of Materials Science and Engineering, Nano Institute of Utah, University of Utah, Salt Lake City, UT 84112, USA; u1320840@utah.edu

* Correspondence: shuaichen@jxstnu.edu.cn (S.C.); lzang@eng.utah.edu (L.Z.); Tel.: +1-801-587-1551 (L.Z.); Fax: +1-801-581-4816 (L.Z.)

check for updates

Citation: Liao, C.; Zhang, M.; Gao, N.; Tian, Q.; Shi, J.; Chen, S.; Wang, C.; Zang, L. Paper-Based Vapor

Detection of Formaldehyde:

Colorimetric Sensing with High

Sensitivity. Chemosensors 2021, 9, 335.

https://doi.org/10.3390/

chemosensors 9120335

Academic Editors: Xudong Wang and Hongshang Peng

Received: 25 October 2021

Accepted: 27 November 2021

Published: 29 November 2021

Publisher's Note: MDPI stays neutral with regard to jurisdictional claims in published maps and institutional affiliations.

Copyright: (c) 2021 by the authors. Licensee MDPI, Basel, Switzerland. This article is an open access article distributed under the terms and conditions of the Creative Commons Attribution (CC BY) license (https:// creativecommons.org/licenses/by/ $4.0 /)$.

\begin{abstract}
We report on a novel colorimetric sensor system for highly sensitive detection of formaldehyde (FA) in the gas phase. The sensor is constructed with paper towel as a substrate coated with the sulfuric acid salt of hydroxylamine $\left(\left(\mathrm{NH}_{2} \mathrm{OH}\right)_{2} \cdot \mathrm{H}_{2} \mathrm{SO}_{4}\right)$ together with two $\mathrm{pH}$ indicators, bromophenol blue and thymol blue. Upon exposure to FA, the hydroxylamine will react with the absorbed FA to form a Schiff base $\left(\mathrm{H}_{2} \mathrm{C}=\mathrm{N}-\mathrm{OH}\right)$, thus releasing a stoichiometric amount of sulfuric acid, which in turn induces a color change of the $\mathrm{pH}$ indicator. Such a color change was significantly enriched by incorporating two $\mathrm{pH}$ indicators in the system. With the optimized molar ratio of the two $\mathrm{pH}$ indicators, the color change (from brown to yellow, and to red) could become so dramatic as to be visible to the eye depending on the concentration of FA. In particular, under $80 \mathrm{ppb}$ of FA (the air quality threshold set by WHO) the color of the sensor substrate changes from brown to yellow, which can even be envisioned clearly by the naked eyes. By using a color reader, the observed color change can be measured quantitatively as a function of the vapor concentration of FA, which produces a linear relationship as fitted with the data points. This helps estimate the limit of detection (LOD), to be $10 \mathrm{ppb}$ under an exposure time of $10 \mathrm{~min}$, which is much lower than the air quality threshold set by WHO. The reported sensor also demonstrates high selectivity towards FA with no color change observed when exposed to other common chemicals, including solvents and volatile organic compounds. With its high sensitivity and selectivity, the proposed paper-based colorimetric sensor thus developed can potentially be employed as a low-cost and disposable detection kit that may find broad application in detecting FA in indoor air and many other environments.
\end{abstract}

Keywords: vapor detection; formaldehyde; colorimetric; paper-based sensor; hydroxylamine

\section{Introduction}

Formaldehyde (FA), a colorless and reactive carbonyl compound that can be produced from various industrial processes via direct release or decomposition of chemical additives. FA has been widely used as a chemical reagent in wood-processing, textiles, construction, medicines, and among others [1]. The wide variety of use provides numerous sources for FA to be released into air environment, resulting in a severe pollution problem. Exposure to FA may cause various adverse health effects, such as skin and eye irritation, central nervous system injury, blindness, and carcinogenicity [2-4]. According to the guidelines set by the World Health Organization (WHO), the safe exposure level of FA in indoor air should not exceed $80 \mathrm{ppb}$ within $30 \mathrm{~min}$ [5]. Thus, it is of great significance and urgent to develop gaseous sensors to detect FA at low concentration levels that can be employed for quick, onsite air quality detection, thus helping ensure public health. 
Many instrumental analysis methods such as spectrophotometry, gas chromatography, and others derived from them have been developed and applied in FA vapor detection. However, most of these instruments are expensive, complicated to operate, and have time consuming sample treatment and detection processes, and are thus not well suited for the quick, portable detection that is crucial for real-time detection of air quality, particularly in remote areas [6-8]. In contrast, chemosensors based on electrochemistry, surface acoustic waves, chemiresistors and other methods provide great potential for being developed into a device that is small in size, and easier to use [9-11], though further development of these sensors is hampered by the typical poor selectivity and low sensitivity (with the limit of detection, LOD usually $>300 \mathrm{ppb}$ for detection of FA). Among all the chemosensors developed thus far, optical chemosensors based on colorimetric or fluorescence modulation usually provide relatively more options for improving the detection sensitivity and selectivity by unique molecular design and structural engineering of the sensors [12-15], which can in turn enhance the chemical binding with gas analytes like FA. Optical chemosensors are also simple in sensing response, ideally based on direct, one-step interaction with the analyte, and can be fabricated into a small, easy-to-use system in low cost, which is adaptable for portable detection or integration into a current air inspection system for quick, quantitative detection of a specific pollutant like FA.

In comparison to fluorescence-based sensors, colorimetric sensors can become more competitive with simplicity in device construction or system miniaturization by removing the need of photoexcitation and detection parts as required for a fluorescence sensor. Indeed, the signal change of colorimetric chemosensors can often be visually recognized by naked eyes without involving complicated optics, thus making the whole detection system simple and quick in operation, as well as low cost. At present, colorimetric sensors for the detection of FA are mostly based on some color change induced directly or indirectly by the chemical reactions between FA and the sensor components, such as $\mathrm{pH}$ indicators [16-20], chromotropic acid [21,22], Fluoral-P [23] or Tollens' reactions [24-26]. Among these sensors, aldimine condensation, i.e., reaction between aldehyde and primary amine producing a Schiff base $\left(\mathrm{R}-\mathrm{C}=\mathrm{N}-\mathrm{R}^{\prime}\right)$, represents a simple, and highly selective sensing approach to detecting aldehydes. In particular, the acidic salts of hydroxylamine have attracted increasing interest in recent years in gas phase detection of FA as the sensing reaction (response) can occur quickly, and the acid thus produced can be measured simultaneously using $\mathrm{pH}$ indicators or chemiresistive sensors based on carbon nanotubes or other materials that are sensitive to interactions with acids (protons) [13,27]. Although the chemiresistive sensors with carbon nanotubes gave low LOD for detection of FA (16 ppb), the colorimetric sensors based on $\mathrm{pH}$ indicators showed much less sensitivity, with LOD barely around the WHO safety threshold ( $80 \mathrm{ppb}$ ) set for FA [20]. The low detection sensitivity is mainly due to that only one $\mathrm{pH}$ indicator (methyl yellow) was employed in the sensor, and the homochromatic response generated from the single-component was not sufficient for detecting small changes in $\mathrm{pH}$ [28]. Therefore, it remains imperative to explore new colorimetric compounds that may provide a heterochromatic response, thus enhancing the measurement of color gradient and further improving the detection sensitivity for FA.

Herein, we report on a novel colorimetric sensor system that can detect FA down to a LOD of $10 \mathrm{ppb}$ with only $10 \mathrm{~min}$ of exposure. As illustrated in Figure 1, the sensor is composed of a paper towel coated with the sulfate salt of hydroxylamine $\left(\mathrm{NH}_{2} \mathrm{OH}\right)_{2} \cdot \mathrm{H}_{2} \mathrm{SO}_{4}$ mixed with two $\mathrm{pH}$ indicators, thymol blue (TB) and bromophenol blue (BPB). The fibril framework of paper towel not only allows for homogeneous coating of the sensing reagents, but also provides open, interconnected porosity for expedient diffusion of gas analytes, which is crucial for vapor detection of chemicals like FA. The colorimetric sensing relies on the specific aldimine condensation reaction between $\left(\mathrm{NH}_{2} \mathrm{OH}\right)_{2} \cdot \mathrm{H}_{2} \mathrm{SO}_{4}$ and $\mathrm{FA}$ to form the corresponding Schiff base $\left(\mathrm{H}_{2} \mathrm{C}=\mathrm{N}-\mathrm{OH}\right)$, thus a releasing stoichiometric amount of $\mathrm{H}_{2} \mathrm{SO}_{4}$ (Equation (1)), which in turn induces a color change of the two $\mathrm{pH}$ indicators. With appropriate optimization of the molar ratio of the two $\mathrm{pH}$ indicators, the color change upon exposure to FA can be maximized in terms of both color gradient and the number 
of discernible colors involved. This results in highly efficient detection of FA with LOD down to $10 \mathrm{ppb}$, which is among the lowest for all the colorimetric sensors reported so far for FA [13]. The sensor also demonstrates high selectivity towards FA in the presence of other common organic solvents and volatile chemicals. Moreover, the enriched color changes associated with the multiple $\mathrm{pH}$ indicators used will also help improve the visual resolution for direct detection by naked eyes. Combination of the high sensitivity, selectivity, simplicity and low cost makes the paper-based colorimetric sensor reported herein to have a great potential to be broadly applied in air quality inspection for FA. As the aldimine condensation reaction between $\left(\mathrm{NH}_{2} \mathrm{OH}\right)_{2} \cdot \mathrm{H}_{2} \mathrm{SO}_{4}$ and FA is irreversible, the paper-based sensor thus developed can be employed as a disposable detection kit, taking advantage of the low-cost.

$$
2 \mathrm{HCHO}+\left(\mathrm{NH}_{2} \mathrm{OH}\right)_{2} \cdot \mathrm{H}_{2} \mathrm{SO}_{4} \rightarrow 2 \mathrm{H}_{2} \mathrm{C}=\mathrm{NOH}+\mathrm{H}_{2} \mathrm{SO}_{4}+2 \mathrm{H}_{2} \mathrm{O}
$$

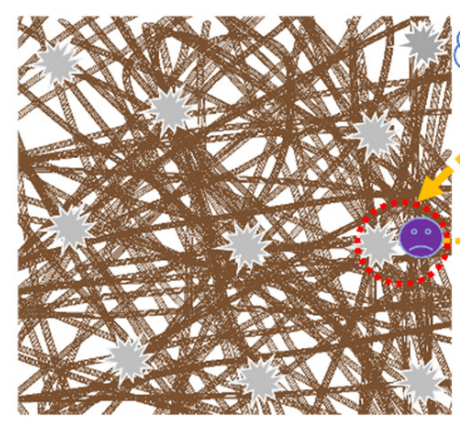

Paper Coated with pH Indicators
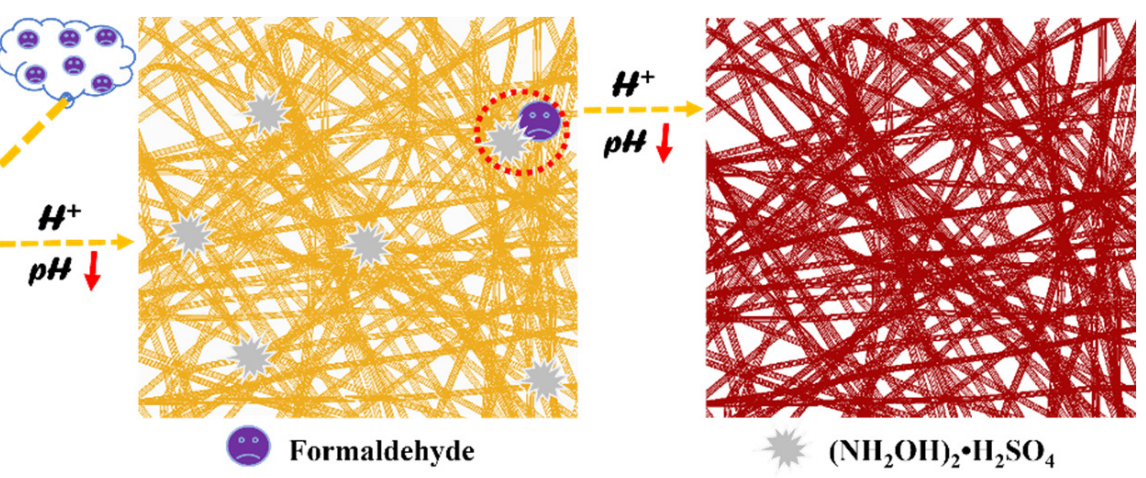

Figure 1. Schematic illustration of the colorimetric sensor for FA based on paper towel coated with $\left(\mathrm{NH}_{2} \mathrm{OH}\right)_{2} \cdot \mathrm{H}_{2} \mathrm{SO}_{4}$ and two $\mathrm{pH}$ indicators, $\mathrm{TB}$ and $\mathrm{BPB}$.

\section{Experimental Methods}

\subsection{Materials}

Formalin solution (37 wt.\% aqueous solution of FA) and $\left(\mathrm{NH}_{2} \mathrm{OH}\right)_{2} \cdot \mathrm{H}_{2} \mathrm{SO}_{4}$ were purchased from J\&K Scientific Ltd. (Beijing, China). Glycerin, methanol, sodium bicarbonate $\left(\mathrm{NaHCO}_{3}\right)$, and other chemicals were all in AR grade and purchased from Aladdin Ltd., (Shanghai, China). The gas sample, such as $\mathrm{CO}_{2}, \mathrm{SO}_{2}$, etc. were purchased from Dalian Special Gases Ltd. (Liaoning, China). The paper towels (white, K-MB05) were purchased from Hangzhou Yuanmian Technology Ltd. (Zhejiang, China). Ultrapure water was generated by an ultrapure water treatment system (EPED-S2-90DF, Nanjing EPED Technology Ltd., Jiangsu, China). The optical images of sensor strips (cut from paper towels) were recorded with a digital camera (Canon 750D; Canon, Tokyo, Japan).

\subsection{Fabrication of Colorimetric Sensing Strips}

The sensor was fabricated as a strip $(1.2 \mathrm{~cm} \times 1.2 \mathrm{~cm})$ cut from a paper towel sheet and coated with $\left(\mathrm{NH}_{2} \mathrm{OH}\right)_{2} \cdot \mathrm{H}_{2} \mathrm{SO}_{4}$ mixed with two $\mathrm{pH}$ indicators, TB and BPB. The paper towel substrate possesses a three-dimensional (3D) interconnected network formed by the intertwined cellulose microfibers. Such a microstructure provides not only large surface area, but also continuous open porosity that is conducive to the diffusion and absorption of gas analytes. Such 3D bulk diffusion allows us to use thick paper towel in order to increase the color density, which helps improve the measurement accuracy, and thus detection sensitivity. Moreover, the paper towel and the sensor reagents involved are all in extremely low cost, especially considering the small size and amount used. This will facilitate the development of the sensor composite into a disposable detection kit, making the onsite measurement to be even easier. In this study, three brands of paper towels were chosen for initial sensor testing, and all the samples showed similar color responses, as shown in Figure S1 in the Supporting Information. One of the three paper towels (No. 1) 
possesses a relatively tighter and more uniform fibril network structure, which combined helps produce stable, homogeneous coating of $\left(\mathrm{NH}_{2} \mathrm{OH}\right)_{2} \cdot \mathrm{H}_{2} \mathrm{SO}_{4}$ and the $\mathrm{pH}$ indicators as revealed by the uniform color distribution throughout the whole area both before and after exposure to FA (Figure S1).

$\left(\mathrm{NH}_{2} \mathrm{OH}\right)_{2} \cdot \mathrm{H}_{2} \mathrm{SO}_{4}$ was chosen as the hydroxylamine acidic salt for development as the detection kit mainly because of its relatively large range of $\mathrm{pH}$ change upon reaction with FA, as well as its high solubility and stability in aqueous solution for repeatable sample preparation. Four other hydroxylamine acidic salts (Table S1) were also selected for screening characterization in aqueous solution under the same conditions. Upon reaction with the same stoichiometric amount of $\mathrm{FA}$, the solution of $\left(\mathrm{NH}_{2} \mathrm{OH}\right)_{2} \cdot \mathrm{H}_{2} \mathrm{SO}_{4}$ demonstrated the largest scale of $\mathrm{pH}$ change, from $\mathrm{pH} 4.0$ to 1.3, whereas all the other four salts showed only one unit of $\mathrm{pH}$ change. The large scale of $\mathrm{pH}$ change allows for more options of $\mathrm{pH}$ indicators to be selected. In this study, TB and BPB were selected as the $\mathrm{pH}$ indicators to provide colorimetric change corresponding to the large $\mathrm{pH}$ change associated with $\left(\mathrm{NH}_{2} \mathrm{OH}\right)_{2} \cdot \mathrm{H}_{2} \mathrm{SO}_{4}$. The color of TB is pink at $\mathrm{pH}$ below 1.2 , changes to orange at $\mathrm{pH} 1.2-2.8$, and finally becomes yellow at $\mathrm{pH}$ above 2.8. The color of $\mathrm{BPB}$ is yellow at $\mathrm{pH}$ below 3.0, changes to turquoise at $\mathrm{pH} 3.0-4.6$, and finally becomes blue at $\mathrm{pH}$ above 4.6. Using the two $\mathrm{pH}$ indicators in the system would provide multiple colors and combinations along the $\mathrm{pH}$ change from 4.0-5.0 to $\sim 1.0$, which covers the range of sensor response between $\left(\mathrm{NH}_{2} \mathrm{OH}\right)_{2} \cdot \mathrm{H}_{2} \mathrm{SO}_{4}$ and $\mathrm{FA}$ as fabricated in the paper towel kit (vide infra). To facilitate the absorption of FA, a hydrophilic reagent such as glycerin was also incorporated into the sensor composition. The high hygroscopicity of glycerin also helps maintain water in the film, which is conducive to the molecular diffusion to expedite the aldimine condensation reaction (Equation (1)), and diffusion of protons to trigger the color change of $\mathrm{pH}$ indicators.

In a typical process of fabricating the sensor strip, a piece of paper towel (cut in $1.2 \mathrm{~cm} \times 1.2 \mathrm{~cm}$ square shape) was immersed for $20 \mathrm{~min}$ in a solution that contains hydroxylamine sulfate, $\mathrm{pH}$ indicators and glycerin. The strip was then taken out of the solution and dried under vacuum at $30{ }^{\circ} \mathrm{C}$ for $30 \mathrm{~min}$. The immersion solution was prepared by dissolving TB (32.1 $\mu \mathrm{mol} ; 0.015 \mathrm{~g})$ and BPB (32.1 $\mu \mathrm{mol} ; 0.021 \mathrm{~g})$ in $45 \mathrm{~mL}$ methanol, followed by adding $15 \mathrm{~mL}$ of water, hydroxylamine sulfate $(3.6 \mathrm{mmol} ; 0.6 \mathrm{~g})$ and $10 \mathrm{~mL}$ of glycerin were added. The solution was then ultrasonicated for $5 \mathrm{~min}$ before immersing in the paper towel strip. The $\mathrm{pH}$ of the solution can be adjusted as needed by adding appropriate amount of $\mathrm{NaHCO}_{3}$. Although the above preparation process used equal molar amount of the two $\mathrm{pH}$ indicators (1:1), the molar ratio of TB and BPB was adjustable. Indeed, in this study we have also fabricated three more sensor strips with TB/BPB ratios of 1:1.5, 1.5:1 and 2:1, and tested their colorimetric sensing along with the one of 1:1 ratio, aiming to identify the composition that gives the best sensor performance.

\subsection{Construction of an Environment Chamber for FA Vapor Generation and Sensor Testing}

An environmental chamber (Figure 2) was designed and constructed to produce FA vapor at varying concentrations under highly controlled temperature and humidity conditions. The chamber consisted of a transparent polymethyl methacrylate (PMMA) box with a volume of $252 \mathrm{~L}$, which houses a heater, a humidifier, temperature and humidity sensors both connected to a controller for adjusting and controlling the inside temperature and humidity. A micro-fan is also included for facilitating the diffusion of gas species, producing homogeneous concentration distribution. The attached pumping system allows for easy, quick generation of FA vapor by connecting to a diffusion flask containing a solution of FA. Varying vapor concentrations of FA in the chamber can be generated by purging the head-space FA from the diffusion flask containing different volumes of formalin solution with a constant flow of air for a controlled length of time. The vapor concentration of FA generated can be calibrated by a PPM-400ST FA Metre (PPM Technology Ltd., Caernarfon, UK). Replacing the diffusion flask and reconnecting with a glass tube containing the paperbased sensor strip allows for testing of the colorimetric response towards FA. The sensor 
strip is fixed at a right position in the glass tube allowing for maximal surface contact to the air flow containing FA. The closed flow circulation helps maintain concentration equilibrium between the chamber and the glass tube, as well as expedite the adsorption of FA. After certain amount of time (say $10 \mathrm{~min}$ ), the sensor strip will be taken out and measured by a color reader. Under such a flow circulation system, the sensor exposure time can be easily adjusted and controlled.

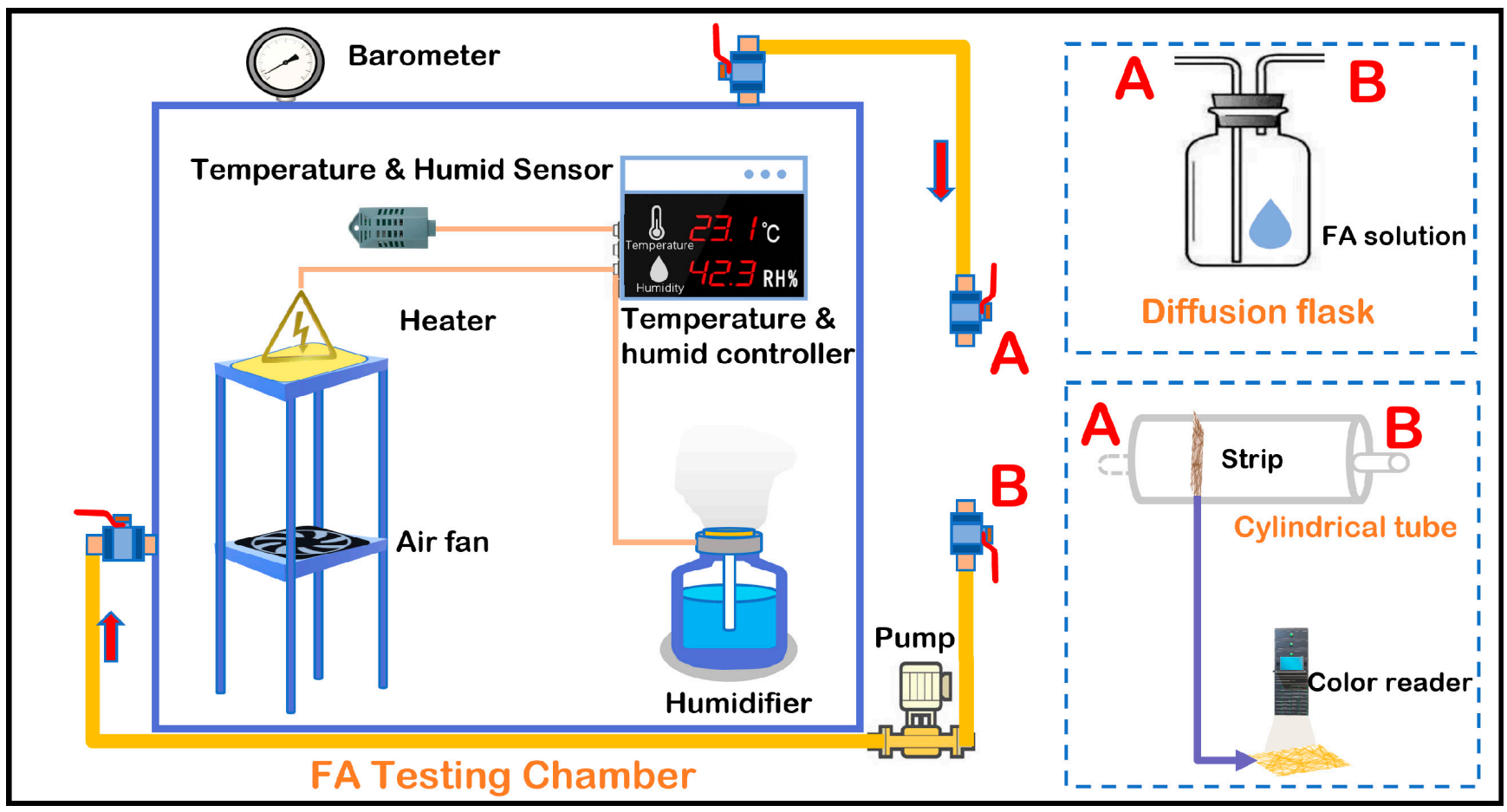

Figure 2. Schematic illustration of the environmental chamber for generation of FA vapor and testing of the colorimetric sensor.

\subsection{Measurement of Color Change}

The color change of sensor strips was measured by a color reader (3nh, Model NR60CP, Shenzhen 3nh Technology Ltd., Guangdong, China). A D65 light source normalized by the International Commission on Illumination (CIE) was used in the color reader, which closely matches the daylight, helping minimizing the measurement errors due to lighting fluctuation [29,30]. $\Delta \mathrm{E}^{*}$ ab value as an index to describe the total color difference (TCD) [31], is calculated following (Equation (2)):

$$
\Delta \mathrm{E}^{*} \mathrm{ab}=\left[(\Delta \mathrm{L})^{2}+(\Delta \mathrm{a})^{2}+(\Delta \mathrm{b})^{2}\right]^{1 / 2}
$$

where $\Delta \mathrm{L}$ is the brightness, $\Delta \mathrm{a}$ the red-green degree, and $\Delta \mathrm{b}$ the yellow-blue degree.

\section{Results and Discussions}

\subsection{Effect of TB/BPB Ratio on Colorimetric Sensing}

The color change of the sensor strips was found to be highly affected by the molar ratio of the two $\mathrm{pH}$ indicators used, TB/BPB. As shown in Figure 3a, for all the four strips with different molar ratios of TB/BPB (1:1, 1:1.5, 1.5: 1 and 2:1) a distinct color change could be easily envisioned, even by naked eyes, when exposed to $10 \mathrm{ppm}$ FA for varying times. Remarkably, all the strips at different exposure stages showed uniform color density throughout the whole area, indicating homogeneous distribution of TB/BPB and $\left(\mathrm{NH}_{2} \mathrm{OH}\right)_{2} \cdot \mathrm{H}_{2} \mathrm{SO}_{4}$ within the paper matrix. By measuring the total color difference using a color reader, the value of $\Delta \mathrm{E}^{*} \mathrm{ab}$ can be plotted as a function of exposure time as shown in Figure 3b, from which one can clearly identify the best TB/BPB ratio of 1:1 that 
demonstrates the strongest color discrimination as indicated by the highest value of $\Delta \mathrm{E}^{*} \mathrm{ab}$. For all the strips under test, the maximal value of $\Delta \mathrm{E}^{*} \mathrm{ab}$ was reached after $5-10 \mathrm{~min}$ of exposure. Further exposure to FA produces more acids, or lower $\mathrm{pH}$, wherein the combined color of TB and BPB becomes less distinct from the initial color before exposure. In the rest of experiments of this study, we kept the molar ratio of TB/BPB as 1:1 in fabricating the sensor strips.
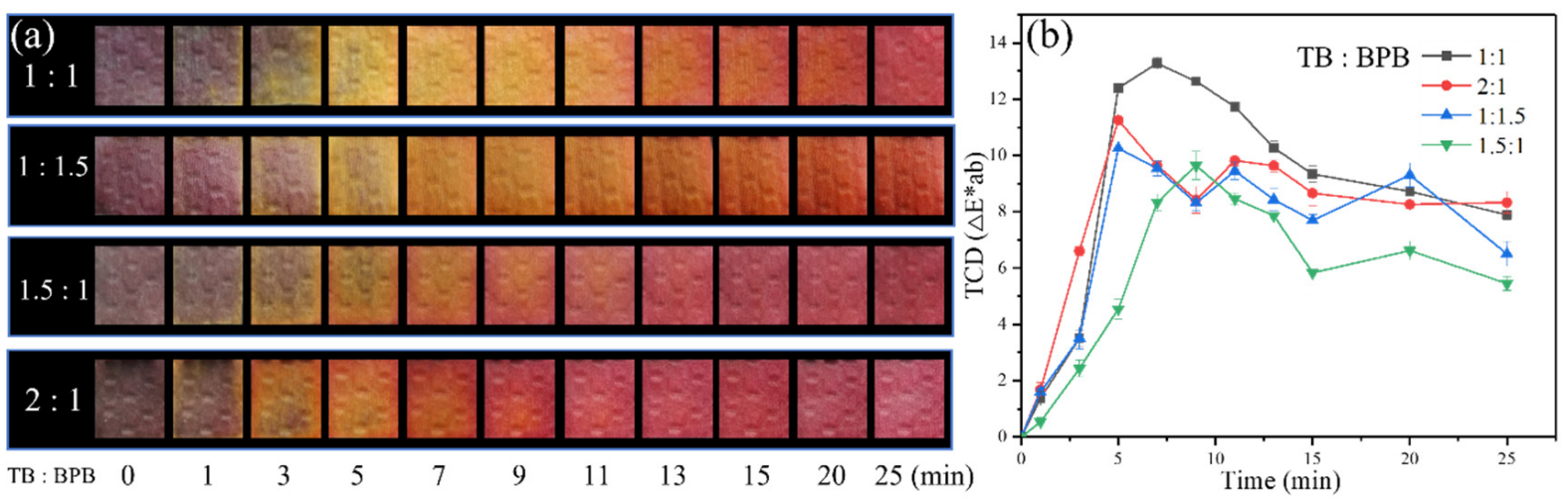

Figure 3. (a) Photos of the four sensor strips with different TB/BPB molar ratios upon exposure to the vapor of FA (10 ppm) for varying times, showing rich color changes. (b) Values of $\Delta \mathrm{E}^{*} \mathrm{ab}$ measured for the samples in (a) plotted as a function of exposure time. The initial $\mathrm{pH}$ value of the immersion solution used for preparing the sensor strip was $4.7 \pm 0.1$, and all measurement were performed at $25^{\circ} \mathrm{C}$ and $60 \% \mathrm{RH}$.

\subsection{Effect of Initial $\mathrm{pH}$ on Colorimetric Sensing}

As the colorimetric sensing (value of $\Delta \mathrm{E}^{*} \mathrm{ab}$ ) is determined by the color difference of a sensor strip before and after exposure to FA, it is critical to define the initial color of the strip, which in turn can be optimized by adjusting the $\mathrm{pH}$. The color of the $\mathrm{pH}$ indicator TB remains as yellow around $\mathrm{pH} 4.6$, while the color of $\mathrm{BPB}$ changes from turquoise to blue from below to above $\mathrm{pH}$ 4.6, so the color of the strip (defined as the combined color of TB and BPB) may be dramatically adjusted around this $\mathrm{pH}$. As shown in Figure $4 \mathrm{a}$, in this study five sensor strips were fabricated by immersing the pieces of paper towel into the solutions adjusted at five different $\mathrm{pH}$ values, 4.00, 4.10, 4.25, 4.50 and 4.89 , all containing the same amount of TB/BPB, $\left(\mathrm{NH}_{2} \mathrm{OH}\right)_{2} \cdot \mathrm{H}_{2} \mathrm{SO}_{4}$ and glycerol. For the two strips fabricated at $\mathrm{pH}=4.00$ and 4.10 , the pristine color was light yellow and dark yellow, respectively. When exposed to FA, the color would eventually change to yellow as observed in Figure 3, so the color difference attained for these two strips would not be significant, thus not conducive to enhancing the sensing efficiency. As the $\mathrm{pH}$ increases, the three strips fabricated at $\mathrm{pH} 4.25,4.50$ and 4.89 developed a dark brown color with increased optical density. When tested for colorimetric sensing upon exposure to the vapor of FA at varying concentrations $(80,200,350,500,800 \mathrm{ppb})$ for $10 \mathrm{~min}$, the three strips demonstrated significant color change with the $\mathrm{pH} 4.25$ one showing the highest value of $\Delta \mathrm{E}^{*} \mathrm{ab}$ (Figure $4 \mathrm{~b}$ ). The decreased color change observed for the strips of $\mathrm{pH} 4.50$ and 4.89 is likely due to the increased color density at pristine state, which otherwise diminishes the color difference in comparison to the dark red color obtained after extensive exposure to FA (as shown Figure 3). With the highest colorimetric sensitivity and richness in color changes, the strip fabricated at $\mathrm{pH} 4.25$ has been used for all the subsequent sensor tests. 

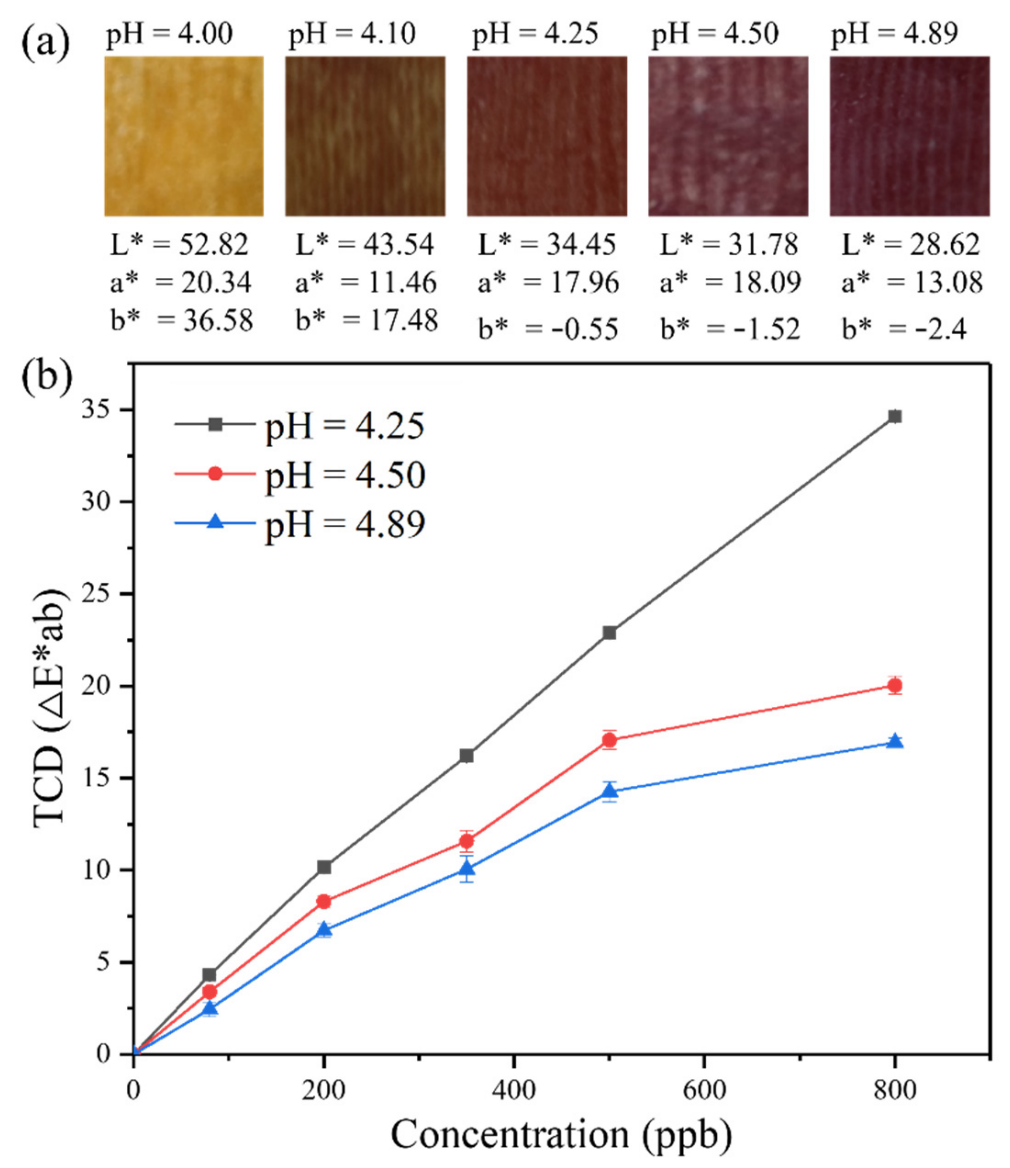

Figure 4. (a) Photos of the five sensor strips fabricated by immersing in the solutions of different $\mathrm{pH}$ values. Values marked underneath the photo are for the brightness $\left(\mathrm{L}^{*}\right)$, position between red and green $\left(a^{*}\right)$, and position between yellow and blue $\left(b^{*}\right)$. (b) The values of $\Delta E^{*} a b$ measured for the three strips after $10 \mathrm{~min}$ of exposure to FA vapor at different concentrations $(80,200,350,500$, $800 \mathrm{ppb}$ ). The measurements were performed at $25^{\circ} \mathrm{C}$ and $45 \% \mathrm{RH}$.

\subsection{Quantitative Assessment of the Sensitivity of Colorimetric Sensing}

Further assessment of the sensing sensitivity was performed on the sensor strip fabricated from the solution of $\mathrm{pH} 4.25$ containing 1:1 TB/BPB as optimized from the above. The color change of the sensor strip was examined by exposure to various concentrations of FA vapor $(0-800 \mathrm{ppb})$ for $10 \mathrm{~min}$. As shown in Figure $5 \mathrm{a}$, the value of $\Delta \mathrm{E}^{*} \mathrm{ab}$ measured by the sensor strip increases linearly with the vapor concentration of FA within the testing range. Linear fitting of the data points gives $\Delta \mathrm{E}^{*} \mathrm{ab}=0.838+0.042 \mathrm{C}$, with a correlation coefficient of 0.991 . If defining three times the standard deviation as the detectable value of $\Delta \mathrm{E}^{*} \mathrm{ab}$, the LOD can be projected to be $10 \mathrm{ppb}$, which is eight times lower than the air quality threshold $(80 \mathrm{ppb})$ set for FA by the WHO. Figure $5 \mathrm{~b}$ shows the photos of the sensor strips after $10 \mathrm{~min}$ of exposure to different concentrations of FA vapor. Even under the lowest concentration of $80 \mathrm{ppb}$ a distinct color change can be easily envisioned by naked eyes, implying the practical feasibility of applying the sensor kit in air detection of FA.

\subsection{Assessment of the Selectivity of Colorimetric Sensing}

To investigate the selectivity of the colorimetric sensor, the same testing was performed be exposing the sensor strip towards many other gases and volatile organic compounds (VOCs), such as $\mathrm{CO}_{2}, \mathrm{SO}_{2}, \mathrm{NO}_{2}, \mathrm{NH}_{3}, \mathrm{DMF}$, THF, $\mathrm{CHCl}_{3}$, toluene, ethanol and methanol under the same experimental conditions. As shown in Figure 6a, despite the much higher vapor concentrations employed, none of the interferent gases or VOCs demonstrated a visible colorimetric response when tested under the same experimental conditions as done for the FA vapor, for which a distinct color change was otherwise observed, easily 
visualized by naked eyes. Comparison of the $\Delta \mathrm{E}^{*}$ ab values thus measured for FA and all the interferents further proves the strong selectivity of the sensor towards FA, as shown in Figure $6 b$.

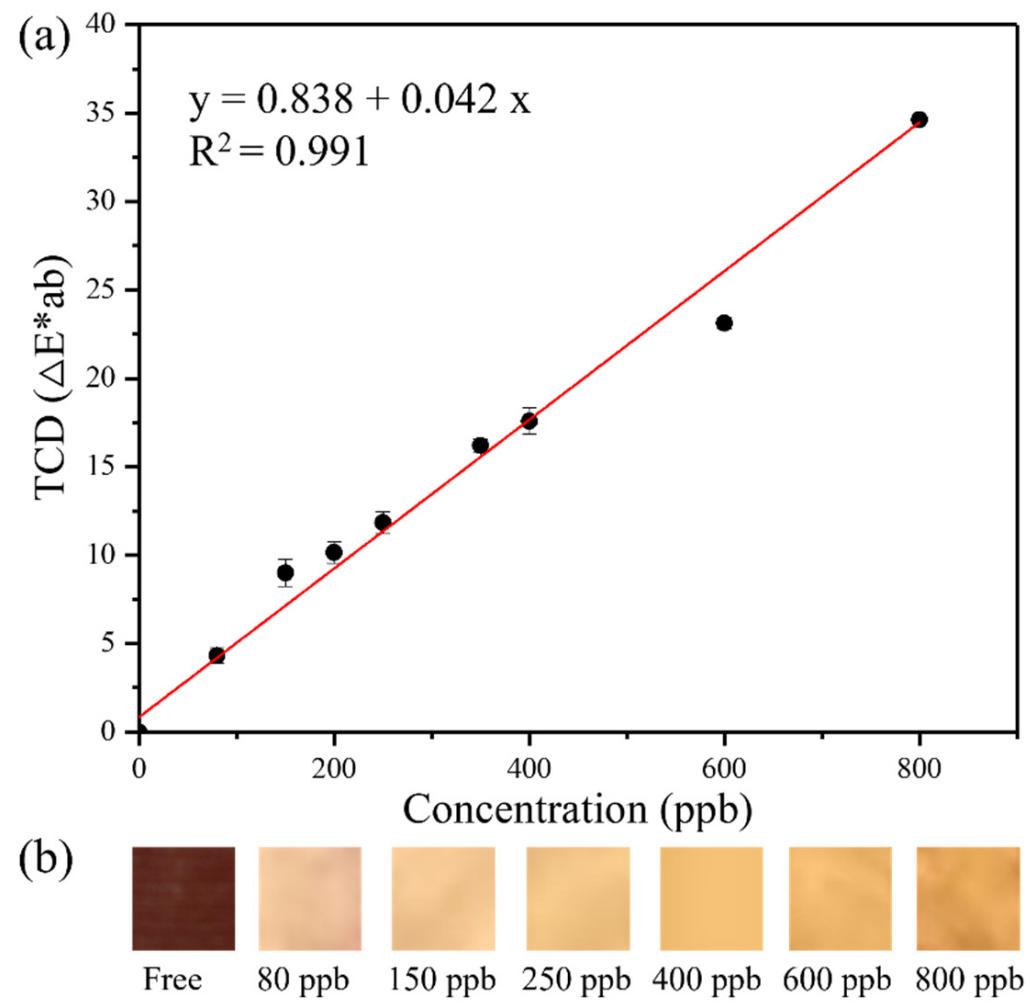

Figure 5. (a) The colorimetric response $\left(\Delta \mathrm{E}^{*} \mathrm{ab}\right)$ versus vapor concentrations of FA. The error bars represent the standard deviations of measurement. (b) Photos of the sensor strips after $10 \mathrm{~min}$ of exposure to different concentrations of FA vapor. The measurements were performed at $25{ }^{\circ} \mathrm{C}$ and $45 \% \mathrm{RH}$.

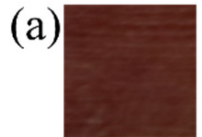

Free

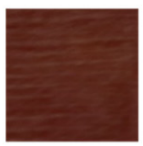

DMF

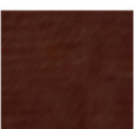

Toluene

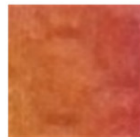

FA

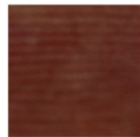

THF

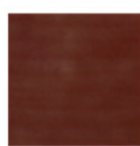

$\mathrm{CHCl}_{3}$

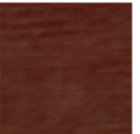

$\mathrm{CO}_{2}$

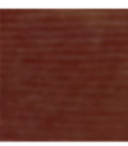

$\mathrm{SO}_{2}$

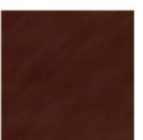

Ethanol Methanol

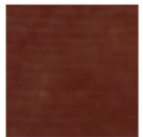

(b)

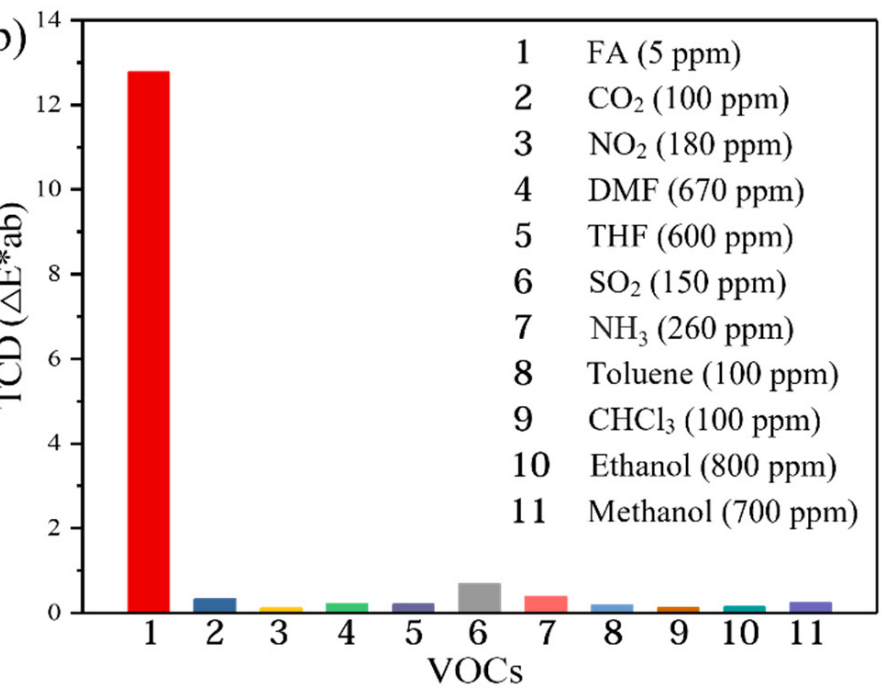

Figure 6. (a) Photos and (b) colorimetric response ( $\Delta \mathrm{E}^{*}$ ab values) of the sensor strips after 10 min of exposure to FA vapor (5 ppm), in comparison with other gases and volatile organic compounds under much higher concentration (marked in the parenthesis). The measurements were performed at $25^{\circ} \mathrm{C}$ and $45 \% \mathrm{RH}$. 


\subsection{Effect of Humidity on Colorimetric Sensing}

Humidity effects are common for all the chemosensors considering the relatively high concentration of moisture under ambient conditions. To explore the humidity effect on the colorimetric sensing described above, the same sensor tests were repeated but under different relative humidity $(\mathrm{RH})$ levels. As shown in Figure 7, within the range of $30-50 \% \mathrm{RH}$ the color response of the sensor strips was almost unaffected, as tested for all four vapor concentrations of FA. However, when the humidity increases above $50 \% \mathrm{RH}$, $\Delta \mathrm{E}^{*} \mathrm{ab}$ values start dropping sharply, and this trend seems to become more obvious when tested for higher concentrations of FA. The decreased sensor response under increased humidity is likely due to the competitive reaction (hydrolysis) between $\mathrm{FA}$ and water, which converts FA to methylene glycol, thus losing the reactivity with $\left(\mathrm{NH}_{2} \mathrm{OH}\right)_{2} \cdot \mathrm{H}_{2} \mathrm{SO}_{4}$, and preventing the generation of free acids [32]. Regarding the humidity effect, the colorimetric sensor reported herein should be calibrated under different humidity levels before it can be deployed in practical applications. There remains a possibility that the color of $\mathrm{pH}$ indicator may be affected by the humidity change. To explore this potential effect, the same sensor strip was tested under the wide range of humidity (up to 95\%). As shown in Figure S2 in the Supporting Information, the color value of the sensor strip remains little changed under the varying humidifies, excluding any significant effect of humidity on the initial color of sensor strip.

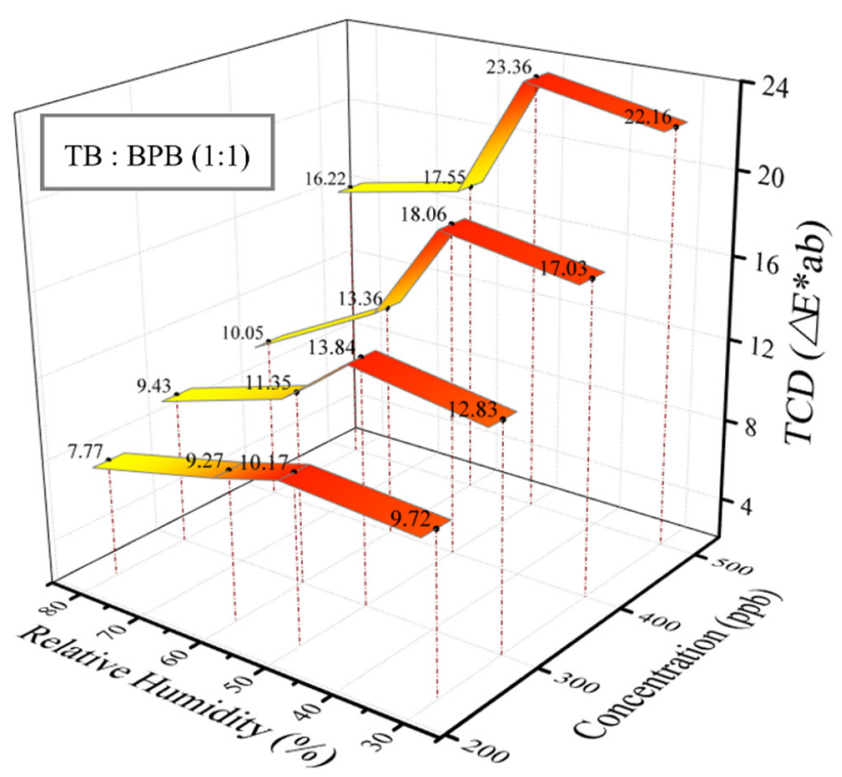

Figure 7. Colorimetric response $\left(\Delta \mathrm{E}^{*} \mathrm{ab}\right)$ of the sensor strips upon exposure to four different vapor concentrations of FA $(230,300,400,500 \mathrm{ppb})$, each tested under varying humidity levels. All experiments were performed at $28^{\circ} \mathrm{C}$.

\section{Conclusions}

We have developed an efficient colorimetric sensing system for the detection of FA in the gas phase. The sensory material is primarily based on cheap paper towels, the cellulose fibril network of which provides a large, open interface for modification with $\left(\mathrm{NH}_{2} \mathrm{OH}\right)_{2} \cdot \mathrm{H}_{2} \mathrm{SO}_{4}$ and $\mathrm{pH}$ indicators that combined enable selective sensor reaction with FA. This disposable paper-based sensor kit provides a simple and quick detection of FA with both high sensitivity and selectivity. A LOD of $10 \mathrm{ppb}$ is projected for the sensor kit when using a color reader, which is much lower than the air quality threshold $(80 \mathrm{ppb})$ set by the WHO. Actually, in the presence of $80 \mathrm{ppb}$ of FA a distinct, color change obtained for the sensor strip can even be visualized by naked eyes. With appropriate calibration of the humidity effect, the reported sensor kit will find broad applications in air detection of FA as a close-to-zero cost approach in comparison to many of the current detection technologies. 
Supplementary Materials: The following are available online at https: / www.mdpi.com/article/ 10.3390/chemosensors9120335/s1, Figure S1: Comparison of colorimetric response of sensor strips fabricated from different paper towels, Table S1: Selection of hydroxylamine acid salts, Figure S2: The stability of the initial color of the sensor strip under different humidity.

Author Contributions: Conceptualization, C.L., S.C., L.Z., C.W.; investigation and original draft preparation, C.L.; revising and test assisting, M.Z., N.G., Q.T., J.S.; review, editing, and project administration, L.Z. and S.C. All authors have read and agreed to the published version of the manuscript.

Funding: We thank the Scientific Research Fund of Shaanxi University of Science and Technology for financial support.

Data Availability Statement: Not applicable.

Conflicts of Interest: The authors declare no conflict of interest.

\section{References}

1. Broek, J.V.D.; Cerrejon, D.K.; Pratsinis, S.E.; Güntner, A.T. Selective formaldehyde detection at ppb in indoor air with a portable sensor. J. Hazard. Mater. 2020, 399, 123052. [CrossRef]

2. Wi, S.; Kim, M.G.; Myung, S.W.; Baik, Y.K.; Lee, K.B.; Song, H.S.; Kwak, M.J.; Kim, S. Evaluation and analysis of volatile organic compounds and formaldehyde emission of building products in accordance with legal standards: A statistical experimental study. J. Hazard. Mater. 2020, 393, 122381. [CrossRef] [PubMed]

3. Han, Z.; Qi, Y.; Yang, Z.; Han, H.; Jiang, Y.; Du, W.; Zhang, X.; Zhang, J.; Dai, Z.; Wu, L. Recent advances and perspectives on constructing metal oxide semiconductor gas sensing materials for efficient formaldehyde detection. J. Mater. Chem. C 2020, 8 , 13169-13188. [CrossRef]

4. Bo, Z.; Yuan, M.; Mao, S.; Chen, X.; Yan, J.H.; Cen, K.F. Decoration of vertical graphene with tin dioxide nanoparticles for highly sensitive room temperature formaldehyde sensing. Sens. Actuators B 2018, 256, 1011-1020. [CrossRef]

5. Zhang, Y.F.; Li, J.Y.; Peng, L.; Ma, M.; Gao, D.J.; Bi, J.; Wu, J.T. Formaldehyde sensing with a parts-per-billion limit of detection by dielectric properties and crystal symmetry optimization in $\mathrm{BiFeO}_{3}$-based p-type solid solution. Sens. Actuators B 2021, 344,130314 . [CrossRef]

6. Cui, X.J.; Fang, G.Z.; Jiang, L.Q.; Wang, S. Kinetic spectrophotometric method for rapid determination of trace formaldehyde in foods. Anal. Chim. Acta 2007, 590, 253-259. [CrossRef]

7. Gong, C.M.; Huang, W.; Liu, J.J.; Wei, F.X.; Yu, J.W.; Si, X.K.; Liu, F.H.; Li, Y.F. Detection and analysis of formaldehyde and unburned methanol emissions from a direct-injection spark-ignition methanol engine. Fuel 2018, 221, 188-195. [CrossRef]

8. Yang, M.; Ospina, M.; Tse, C.; Toth, S.; Caudill, S.P.; Vesper, H.W. Ultraperformance liquid chromatography tandem mass spectrometry method to determine formaldehyde hemoglobin adducts in humans as biomarker for formaldehyde exposure. Chem. Res. Toxicol. 2017, 30, 1592-1598. [CrossRef] [PubMed]

9. Calestani, D.; Mosca, R.; Zanichelli, M.; Villani, M.; Zappettini, A. Aldehyde detection by ZnO tetrapod-based gas sensors. J. Mater. Chem. 2011, 21, 15532-15536. [CrossRef]

10. Devkota, J.; Ohodnicki, P.R.; Greve, D.W. SAW sensors for chemical vapors and gases. Sensors 2017, 17, 801. [CrossRef] [PubMed]

11. Xie, H.F.; Sheng, C.H.; Chen, X.; Wang, X.Y.; Li, Z.; Zhou, J. Multi-wall carbon nanotube gas sensors modified with amino-group to detect low concentration of formaldehyde. Sens. Actuators B 2012, 168, 34-38. [CrossRef]

12. Duan, W.; Liu, A.; Li, Q.; Li, Z.W.; Wen, C.Y.; Cai, Z.X.; Tang, S.M.; Li, X.Y.; Zeng, J.B. Toward ultrasensitive and fast colorimetric detection of indoor formaldehyde across the visible region using cetyltrimethylammonium chloride-capped bone-shaped gold nanorods as "chromophores". Analyst 2019, 144, 4582-4588. [CrossRef] [PubMed]

13. Liao, C.L.; Shi, J.F.; Zhang, M.; Dalapati, R.; Tian, Q.Y.; Chen, S.; Wang, C.Y.; Zang, L. Optical chemosensors for the gas phase detection of aldehydes: Mechanism, material design, and application. Mater. Adv. 2021, 2, 6213-6245. [CrossRef]

14. Guo, X.L.; Chen, Y.; Jiang, H.L.; Qiu, X.B.; Yu, D.L. Smartphone-based microfluidic colorimetric sensor for gaseous formaldehyde determination with high sensitivity and selectivity. Sensors 2018, 18, 3141. [CrossRef]

15. Lin, C.F.; Zan, H.W.; Lu, C.J.; Meng, H.F.; Soppera, O. A low-cost miniaturized colorimetric sensor with vertically-stacked semi-transparent finger-type organic photo detector for formaldehyde sensing. Org. Electron. 2019, 73, 115-121. [CrossRef]

16. Engel, L.; Benito-Altamirano, I.; Tarantik, K.R.; Pannek, C.; Dold, M.; Prades, J.D.; Wöllenstein, J. Printed sensor labels for colorimetric detection of ammonia, formaldehyde and hydrogen sulfide from the ambient air. Sens. Actuators B 2021, 330, 129281. [CrossRef]

17. Meng, Q.H.; Han, T.; Wang, G.Q.; Zheng, N.; Cao, C.X.; Xie, S.A. Preparation of a natural dye doped Ormosil coating for the detection of formaldehyde in the optical gas sensor. Sens. Actuators B 2014, 196, 238-244. [CrossRef]

18. Wang, X.Q.; Li, Y.; Li, X.Q.; Yu, J.Y.; Al Deyab, S.S.; Ding, B. Equipment-free chromatic determination of formaldehyde by utilizing pararosaniline-functionalized cellulose nanofibrous membranes. Sens. Actuators B 2014, 203, 333-339. [CrossRef]

19. Wang, X.F.; Si, Y.; Wang, J.L.; Ding, B.; Yu, J.Y.; Al Deyab, S.S. A facile and highly sensitive colorimetric sensor for the detection of formaldehyde based on electro-spinning/netting nano-fiber/nets. Sens. Actuators B 2012, 163, 186-193. [CrossRef] 
20. Nakano, N.; Nagashima, K. An automatic monitor of formaldehyde in air by a monitoring tape method. J. Environ. Monit. 1999, 1, 255-258. [CrossRef] [PubMed]

21. Hauksson, I.; Pontén, A.; Gruvberger, B.; Isaksson, M.; Engfeldt, M.; Bruze, M. Skincare products containing low concentrations of formaldehyde detected by the chromotropic acid method cannot be safely used in formaldehyde-allergic patients. Br. J. Dermatol. 2016, 174, 371-379. [CrossRef] [PubMed]

22. Pretto, A.; Milani, M.R.; Cardoso, A.A. Colorimetric determination of formaldehyde in air using a hanging drop of chromotropic acid. J. Environ. Monit. 2000, 2, 566-570. [CrossRef]

23. Wang, X.Q.; Si, Y.; Mao, X.; Li, Y.; Yu, J.Y.; Wang, H.P.; Ding, B. Colorimetric sensor strips for formaldehyde assay utilizing fluoral-p decorated polyacrylonitrile nanofibrous membranes. Analyst 2013, 138, 5129-5136. [CrossRef] [PubMed]

24. Wang, Y.S.; Guan, M.T.; Yan, X.X.; Lei, Y.Y.; Shen, X.; Luo, L.Q.; He, H.B. Gold nanorods assisted silver mirror reaction for consecutive color change based on-site visual semi-quantification of indoor formaldehyde. Atmos. Environ. 2021, $246,118101$. [CrossRef]

25. Li, J.W.; Wang, Y.; Zhang, Q.H.; Huo, D.Q.; Hou, C.J.; Zhou, J.; Luo, H.B.; Yang, M. New application of old methods: Development of colorimetric sensor array based on Tollen's reagent for the discrimination of aldehydes based on Tollen's reagent. Anal. Chim. Acta 2020, 1096, 138-147. [CrossRef] [PubMed]

26. Chaiendoo, K.; Sooksin, S.; Kulchat, S.; Promarak, V.; Tuntulani, T.; Ngeontae, W. A new formaldehyde sensor from silver nanoclusters modified Tollens' reagent. Food Chem. 2018, 255, 41-48. [CrossRef]

27. Ishihara, S.; Labuta, J.; Nakanishi, T.; Tanaka, T.; Kataura, H. Amperometric detection of sub-ppm formaldehyde using singlewalled carbon nanotubes and hydroxylamines: A referenced chemiresistive system. ACS Sens. 2017, 2, 1405-1409. [CrossRef] [PubMed]

28. Wen, C.Y.; Chen, Y.Z.; Liu, R.S.; Huang, J.K.; Wang, D.W.; Cao, Z.J.; Meteku, B.; Zeng, J.B. Matrix colorimetry for high-resolution visual detection of free cyanide with Au@Au-Ag yolk-shell nanoparticles. J. Mater. Chem. C 2021, 9, 4661-4669. [CrossRef]

29. Gralak, B.; Tayeb, G.; Enoch, S. Morpho butterflies wings color modeled with lamellar grating theory. Opt. Express 2001, 9, 567-578. [CrossRef] [PubMed]

30. Martínez-Domingo, M.Á.; Melgosa, M.; Okajima, K.; Medina, V.J.; Collado-Montero, F.J. Spectral image processing for museum lighting using CIE LED illuminants. Sensors 2019, 19, 5400. [CrossRef]

31. Pedreschi, F.; Moyano, P.; Kaack, K.; Granby, K. Color changes and acrylamide formation in fried potato slices. Food Res. Int. 2005, 38, 1-9. [CrossRef]

32. Szlosek, D.; Currie, D. Application and mechanism of malonic acid as a green alternative for protein-crosslinking. Green Sustain Chem. 2016, 6, 110-115. [CrossRef] 